\title{
KERNEL FUNCTION BASED INTERIOR-POINT ALGORITHMS FOR SEMIDEFINITE OPTIMIZATION
}

\author{
Yong-Hoon LeE, Jin-HeE Jin AND GyeONG-Mi CHO
}

Abstract. We propose a primal-dual interior-point algorithm for semidefinite optimization(SDO) based on a class of kernel functions which are both eligible and self-regular. New search directions and proximity measures are defined based on these functions. We show that the algorithm has $\mathscr{O}\left(\sqrt{n} \log \frac{n}{\varepsilon}\right)$ and $\mathscr{O}\left(\sqrt{n} \log n \log \frac{n}{\varepsilon}\right)$ complexity results for small- and large-update methods, respectively. These are the best known complexity results for such methods. This is the first algorithm for SDO based on this kernel function, as far as we know.

Mathematics subject classification (2010): 90C51, 90C22.

Keywords and phrases: semidefinite optimization; interior-point method; primal-dual method; smalland large-update method; polynomial complexity.

\section{REFERENCES}

[1] Y. Q. BAI, M. E. GHAmi AND C. Roos, A new efficient large-update primal-dual interior-point method based on a finite barrier, SIAM Journal on Optimization 13 (2003), 766-782.

[2] Y. Q. BAI, M. E. GHAMI AND C. Roos, A comparative study of kernel functions for primal-dual interior-point algorithms in linear optimization, SIAM Journal on Optimization 15 (2004), 101-128.

[3] G. M. СHO, An interior-point algorithm for linear optimization based on a new barrier function, Applied Mathematics and Computation 218 (2011), 386-395.

[4] M. E. GHAMI, Y. Q. BAI AND C. Roos, Kernel-function based algorithms for semidefinite optimization, RAIRO Operations Research 43 (2009), 189-199.

[5] M. E. Ghami, Z. A. Guennoun, S. Bouali And T. Steihaug, Interior-point methods for linear optimization based on a kernel function with a trigonometric barrier term, Journal of Computational and Applied Mathematics 236 (2012), 3613-3623.

[6] M. E. Ghami, C. Roos And T. STeIHAUG, A generic primal-dual interior-point method for semidefinite optimization based on a new class of kernel functions, Optimization Methods and Software 25 (2010), 387-403.

[7] R. A. Horn And C. R. Johnson, Topics in matrix analysis, Cambridge University Press, 1991.

[8] M. K. Kim, Y. Y. CHO AND G. M. CHO, New path-following interior-pooint algorithms for $P_{*}(\kappa)$ nonlinear complementarity problems, Nonlinear Analysis: Real World Applications 14 (2013), 718 733.

[9] E. DE KLERK, Aspects of semidefinite programming: interior point algorithms and selected applications, Kluwer Academic Publishers, 2002.

[10] Y. H. LEE, Y. Y. CHO, J. H. JIN AND G. M. CHO, Interior-point algorithms for LO and SDO based on a new class of kernel functions, Journal of nonlinear and convex analysis 13 (2012), 555-573.

[11] Y. NESTEROV AND M. J. TODD, Self-scaled barriers and interior-point methods for convex programming, Mathematics of Operations Research 22 (1997), 1-42.

[12] J. Peng, C. Roos And T. Terlaky, Self-Regularity, A new paradigm for primal-dual interior-point algorithms, Princeton University Press, 2002.

[13] C. Roos, T. TERLAKY AND J. P. ViaL, Theory and algorithms for linear optimization, an interior approach, John Wiley and Sons, Chichester, U.K., 1997.

[14] G. Q. WANG AND Y. Q. BAI, A class of polynomial primal-dual interior-point algorithm for semidefinite optimization, Journal of Shanghai University 10 (2006), 198-207. 
[15] G. Q. WANG, Y. Q. BAI AND C. Roos, Primal-dual interior-point algorithms for semidefinite optimization based on a simple kerenl function, Journal of Mathematical Modelling and Algorithms 4 (2005), 409-433.

[16] H. Wolkowicz, R. Saigal and L. Vandenberghe, Handbook of semidefinite programming, theory, algorithms and applications, Kluwer Academic Publishers 2000 